\title{
Bile Duct Perforation
}

National Cancer Institute

\section{Source}

National Cancer Institute. Bile Duct Perforation. NCI Thesaurus. Code C78528.

A rupture in the wall of the extrahepatic or intrahepatic bile duct due to traumatic or pathologic processes. 